\title{
TikTok and Short-Form Screendance Before and After Covid
}

Moderator: Alexandra Harlig, University of Maryland, College Park

Crystal Abidin, Curtin University

Trevor Boffone, University of Houston

Kelly Bowker, University of California, Riverside

Colette Eloi, University of California, Riverside

Pamela Krayenbuhl, University of Washington Tacoma

Chuyun Oh, San Diego State University

This roundtable was presented on 12 March 2021 as part of the symposium connected to this special issue, This Is Where We Dance Now: Covid-19 and the New and Next in Dance Onscreen. It has been edited for clarity and length. The video of the full roundtable conversation and $\mathrm{Q}+\mathrm{A}$ is viewable at: https://doi.org/10.18061/ijsd.v12i0.8348

ROUNDTABLE

TIKTOK AND SHORT-FORM

SCREENDANCE BEFORE AND AFTER COVID

With Crystal Abidin, Trevor Boffone,

Kelly Bowker, Colette Eloi, Chuyun

Oh, and Pamela Krayenbuhl

Moderated by Alexandra Harlig

Friday, March 12

$5 \mathrm{pm} \mathrm{LA} \mathrm{/} \mathrm{8pm} \mathrm{NYC} \mathrm{/}$

1am (13/3) London /

$12 \mathrm{pm}(13 / 3)$ Sydney

THIS IS WHERE WE DANCE NOW

COVID-19 AND THE NEW AND NEXT IN DANCE ONSCREEN

THE OHIo STATE University
GLOBAL ARTS + HUMANITIES DISCOVERY THEME

Photo by Elena Benthaus, used with permission. Design by Regina Harlig. 
Keywords: Covid-19, TikTok, Dubsmash, dance challenges, popular screendance, appropriation, platform specificity, congregational global body, \#Jerusalema, Zoomers, \#Blacklivesmatter, influencer, Dance Central, face dance, algorithm, viral, privilege, entrapment

Alexandra Harlig: I'm very excited to be moderating tonight as we discuss dance on TikTok and other short form video platforms as they have developed over the last year in particular. Our presenters will each give short remarks and then I'll pose some questions and we'll have some time for questions from the audience at the end.

Crystal Abidin: Here are five provocations on TikTok based on my forthcoming book TikTok and Youth Cultures coming out next year. First, let's think about curation. On TikTok the audio meme is the sorting vehicle or the organizing principle for content. So what this means for a lot of performers - especially for myself as a trained musician-is that we tend to connect the memory of the audio to the bodily performance. So if we hear something, immediately some people break into muscle memory and perform that TikTok dance. And that primacy of audio over the physical and the fleshiness is quite interesting. So think about this as earworms leading the way and shaping how we make use of dance on TikTok.

The second provocation is in relation to creation. On TikTok, technical expertise is really important for visual narrativity; we think about transitions, cuts, the vernacular of trends. We've got a whole layer of celebrity on TikTok whose expertise is teaching people how to do these cuts and transitions, and the knowledge share of the performance of the app-of all the technical knowledge and skills-is an add-on in relation to your knowledge of dance and performance. So there are people who may groom both different sets of expertise, and then there are people who can bring both together, and end up being TikTok stars.

Provocation three looks at competition. You may remember that on TikTok you are able to click into an audio meme and look at all the traceable histories of videos that have used a sound, and that traceable history tends to foster competitive ranking. Most of the time the first video in the audio meme stream is the originating video, and thereafter all the other videos are not sorted chronologically, neither are they sorted by order of the popularity, but rather in batches. So in the first batch you see those who've got millions of engagements, followed by $500 \mathrm{k}$ and above, $100 \mathrm{k}$ to $500 \mathrm{k}$, and so on. Creators who are posting TikTok videos are competing within each of these tiers in order to be seen. What happens here is there's often a lot of conversation and wrestling over people trying to step over each other in the rank, or play within their ranks. To put this more cheekily: "if I cannot play with the kids in the big leagues and the millions of followers, I'm going to remain amateurish and play within my league and become the big fish in a small pond, rather than worm my way and be a little little fish in the very big pond." 
Number four looks at circulation. On TikTok, remix cultures are built into the platform norm; my friends Meg Zeng, Xu Chen, as well as Bondy Kaye wrote a paper describing creativity on TikTok as a type of "circumscribed creativity," where all the features of the platform shape you to create content in specific ways. So while you believe you've got flexibility, this platform is really squishing you into a template and teaching you how to perform creativity within a box. Now, the consequences of this platform norm is that ownership and authorship is often in tension with spreadability; on the one hand you see people performing feeling so happy that millions of people are using their dance, on the other hand every half an hour there are people calling out each other for not acknowledging them. Sometimes the most menial things like a hand sign that goes from the left to the right showing a twist have TikTokers coming up in arms with each other going, 'you stole my idea!' 'You stole my move!' and we're now breaking down to these micro interactions and micro-wrestles of ownership for even the most mundane of bodily symbols.

The fifth and last provocation looks at commerce. On TikTok, visibility does not naturally convert to celebrity or leverage and this is because in this platform, post-based virality takes precedence over persona-based virality. You will see that there are lots of lowerend mid-tier TikTok accounts-you've got one or two viral videos and the rest of the content not registering anything. And in order to get a leg up in that game, they end up repeating the same tweak or the same format of that one viral post over and over. And to try and circumvent the algorithm, they try their very best to blend this core originator viral video with other trends, but they can never really stray far away from the one trick pony that got them viral in the first place. So, we've got curation, creation, competition, circulation, and commerce.

Trevor Boffone: I want to talk to you all about Dubsmash, a dance challenge app that quickly became one of the most popular social media dance places among Black teens in the US in October 2018. In my upcoming book, Renegades: Digital Dance Cultures from Dubsmash to TikTok, I interrogate the roles that Dubsmash, social media, and hip hop music and dance play in youth identity formation in the United States. It explores why Generation Z-or so-called Zoomers-use social media dance apps to connect, how they use them to build relationships, how race and other factors of identity play out through these apps, how social media dance shapes a wider cultural context, and ultimately how community is formed.

These Black Zoomer artists [referring to image on screen] Jalaiah Harmon, who was the one that created the Renegade dance, Brooklyn Queen, Kayla Nicole Jones, and my high school students have become key agents in culture creation and dissemination in the age of screendance. They are some of today's most influential content creators, even if they lack widespread name recognition. Their artistic contributions have come to define a generation and Renegades tells their stories. 
We are in the middle of a major cultural moment in which Zoomers are stirring change through social media performance. This was no more apparent during the summer of 2020. As the Covid-19 pandemic waged on and the country became engulfed in the renewed Black Lives Matter protests following the murder of George Floyd, one thing became abundantly clear-Dubsmashers had mobilized. They were making "moves" on the streets in much the same way they had been doing on social media. And, as always, these teens advocated for racial justice through screendance. With a platform comes great responsibility, and these Zoomers didn't back down.

As Dubsmashers attended BLM marches and used their social media platforms to elevate Black voices, at the same time there was a new dance challenge in the works. On June $5^{\text {th }}$, the Dubsmash Instagram account posted a collection of dubs set to the song "Black Lives Matter" by Dae Dae featuring London on Da Track. The primary dance, choreographed by well-known Dubsmasher @Niyahgotcurls, had all of the hallmarks of a viral dance challenge, combining standard Zoomer dance moves such as the Woah, the Wave, and the Clap, with moves invoking BLM such as freezing with one's hands up and the Black Power fist. At the end of the dance, Niyah holds out her hands, inviting in viewers before the words "\#Blacklivesmatter" appear. While other dancers offered their own spin on the challenge, Niyah's version gained the most virality, likely due to her popularity on Instagram and Dubsmash. Even so, nearly every version of the dance featured the hands up and the Black Power fist, marking these dance moves as an essential part of the viral dance repertoire in the wake of the continued oppression of the Black community at the hands of White supremacy.

The \#BlackLivesMatter dance challenge conveys how this cohort of Black teens uses Dubsmash dance trends and aesthetics to push against mainstream notions of civility and identity. These dancers use digital platforms and hip hop culture to push against the pervasive whiteness, and corresponding white supremacy, in mainstream US pop culture as seen on other apps such as Instagram and TikTok, where clicktivism and black squares are the norm. In 2020, this was even more apparent. Dubsmashers were not going to let this moment pass them by. Even though they may be young, this is the world they have grown up in and it's the one they're ready to transform. Having a viral social media platform was unthinkable when I graduated high school in (year redacted), yet this is the reality of Dubsmashers and other members of Generation Z who are coming-of-age in a digital world. They are not just the next generation of activists, artists, influencers, and leaders; they are the present. And, as this collective work reveals, the revolution will be Dubsmashed.

Kelly Bowker: In my dissertation research I have been looking at the original Dance Central video game as it was created for the Xbox using the Microsoft Kinect. One thing that I examined in that study is a language of authenticity that got circulated with the game. For example, two comments from press about the game say: "If you're serious about learning new dance moves ... buy Dance Central 2." And "If you're looking for the true dancing experience... 'Dance Central 3 ' is the boogie machine for you." And the 
game's creators said: "They can do it in their living room and learn a real skill. And now, when I go to my next wedding — where I used to sit out — I can actually do a few things."

My concern was that there's language being attached to it in terms of "this really teaches you to dance," while the choreography for the game is actually very tailored because of the technology, and the Kinect's tracking system, which does a really poor job with the dance styles that are performed in the game. If you compare images of the choreographer of a particular dance, an avatar during game play, and a woman performing the dance, who notes in her YouTube comments that she gets 100, and labels herself as an expert; she says, "I'll show you how to get 100." Looking at screenshots of these dancers at the same moment in the choreography, you can see that the movement becomes less angular, and more vertical. In other words, the Africanist aesthetics are being evacuated from the dance. And that happens throughout the dance and throughout the game. We see the choreographer with extreme lean and deep knee-bend, the avatar is a little more vertical, and then the gamer is almost completely upright. And one of the things about this particular gamer: she has over 3,000 subscribers on YouTube, and she has over 500 videos; in the morning she posted a video that when I saw it at only 4 hours old, already had 36 views, 11 likes, and 4 comments.

So there's an ongoing community, and my questions in relation to the topic of TikTok are: in terms of TikTok, does the game continue, and how does the game continue to circulate? Does the rhetoric of authenticity that game creators and early press tied to the game continue to be picked up by game players? And then how does the movement change when the game moves to TikTok? The game certainly is on TikTok; people post screen shares of them playing the game, and people post videos of them doing the dance moves. Sometimes it's really clear that they're playing the game, because they're looking past their phone at a screen to know what move to do next, but a lot of times they're doing the moves from memory, they've done these dances so many times.

One example is an account with the username 2000snostalgia7, and you can see the community that's being created, because they post their next video based on the comments that on their previous videos of what songs people want to see next. You can see in a comment at the top of their video: "move your body been asking." As in, "I've been asking you to do this dance," so in this video they are performing the dance to the song "Move Your Body." I think their username and hashtags really capture the essence of what a lot of the members of this community are interested in, which is nostalgia for a game that they played as a kid. A lot of people talk about how when a certain song comes on, they just do the moves, they know them from memory, and also that a large number of young women had a crush on a particular avatar.

As far as the rhetoric of authenticity, it does get attached to the game as it continues on in TikTok. This women's caption at the top says, "y'all talking about Just Dance but can 
we PLEASE acknowledge the most underrated (and superior) game Dance Central?" And a few of the comments on her video say "yessss Dance Central was better. You had to use your whole body," "finally!! it was actually choreography. I love it so much" and "Dance Central had the real dances." These kinds of comments appear not just on her video but on other Dance Central videos. A lot of people note that this is how they learned to dance, that they do these moves at the club, and one particular person learned an entire Dance Central dance, auditioned for the dance team, and was accepted.

As far as my question about whether or not the African aesthetics get evacuated in the same way on TikTok, I think that something different might actually happen because there does seem to be so much communication amongst the community on TikTok. In the screenshot, you can see up in the right-hand corner there's a little box with a silhouette in it. That is the silhouette of the dancer as it's being recorded by the Kinect. And in one of the videos that I looked at, people were just ripping this dancer to shreds in the comments, saying, "you're offbeat," "you're not even doing the dance!" While the feedback system of the Kinect might score someone to get $100 \%$, the community might give them different feedback.

Colette Eloi: I am interested in how pre-colonial African worldviews and ideas of self in dance provide an increased understanding of contemporary Black dance, like those we see on TikTok. With respect to this roundtable discussion, "What is the Next and the New for TikTok?" I cannot say what will be "New," but I do know that it must include a further decolonized perspective of Black Dance, one that seeks out pre-colonial ideologies of the African cultures that have contributed much to the world and to dance on TikTok; ideas of sacred versus social must be further analyzed, along with ideas about the body, and body parts.

I think it's necessary to mention the global Afrobeat music trend, and specifically the song with its hymn-like meanings of transcendence, "Jerusalema," written by Master KG with vocals by singer/songwriter Nomcembo Zikode, released in November 2019. The song itself was wildly popular shortly following its release; however, it was the TikTok \#JerusalemaDanceChallenge that fueled its global reach. Angolan group Fenomenos do Semba recorded themselves dancing a super laid-back, electric slide-like dance routine while eating and holding plates and pots, igniting the dance challenge and making the popularity of the song reach biblical proportions. With more than 85 million Spotify streams, 1 billion views on TikTok, and 812 million dance creations through the challenge, the song "Became a Global Hit Without Ever Having to Be Translated," according to Rolling Stone's October 2020 article.

My analysis of Jerusalema revealed that African-rooted dance can be understood as a kinetic medicinal frequency that like-minded community members generate and apply in the face of change and turmoil. This is in fact very similar to the purpose of dance in precolonial cosmologies from Africa as found in the Bantu-Kongo, Ewe-Fon and in the 
Mali-Senegambia regions. As such, the \#JerusalemaDanceChallenge on TikTok was a manifestation of African dance technology in the way it soothes a crisis with joy, with joint community togetherness. The release of this song coincides with the toxic twin traumas of the Covid Pandemic and the George Floyd Murder and the global protests. The projecting of being at ease that is embodied in the steps and lyrics of Jerusalema, seemed to be a remedy and met the desire of the world for transcendence. What makes this challenge unlike others on TikTok is that so-called "non-dancers" danced: entire police departments, firefighters, funeral homes, scientists, business people, entire airline crews, nursing homes, butchers, people with walkers and in wheelchairs, soldiers in riot gear, soccer players, celebrities, every way of life was represented.

For this roundtable, I would like to offer the idea of the Congregational Global Body. Not limited to the church, my idea of the congregational global body is my philosophical expansion of the Nigerian Lucumi pre-colonial ideology of Ara or person. More than the physical body, the Ara is built by community - a new divine whole body that extends beyond the limbs of the dancer into the cosmos; the body is not just the individual but the congregational body, including dancers, singers, musicians, and audience members, engaged in raising positive energy. In the case of TikTok trends like Jerusalema, the social media platform/screen facilitates the congregational global body, creating a balance in the world in their shared resonance that extends beyond their reach.

The enlivened congregational global body of Jerusalema speaks, it unites the voices of the many; it votes; it signifies life, unity, and humanistic values. It soothes pain. It is generous and abundant. It shuns the power of fear and even of illness. It promotes inclusivity and individuality. It performs and incites well-being. It embraces sexuality and joy and enacts through body, mind, and spirit, holding a diverse and complex array of expressions and meanings. This is what I came to understand after watching hours of these videos. Essential workers dance through the hospital with people on ventilators. One clergyman from a parish in Mumbai said that his congregation's video performing Jerusalema was about "Unity in Diversity." In another video a queer youth puts his individual aesthetic into the seemingly set choreography and is embraced. Another priest posted his congregation dancing, quoting bible verse Jeremiah 3:16, in an act of hope and danced prayer stating, "We Will Dance Again."

The TikTok screen created the congregational global dance body rooted in pre-colonial Black/African culture, which is based in raising healing frequency to activate wholeness. The corporeality of ease, the recognition of all those who are now on the other side, the coming together due to shared conditions, shifts what might be social to sacred. Much has changed; traditional dance that is usually learned over years can be transmitted in one evening of binge watching TikTok. Surprisingly, the sacredness of the dance was retained in the Afrobeat dance Jerusalema to a detectable degree. My closing provocations are: Can the sacredness of dance co-exist with the desire to go viral? Is 
Black culture being erased or widely disseminated through TikTok like platforms? Can TikTok and Social Media screens facilitate Global harmony?

Chuyun Oh: Today, I am going to talk about TikTok dance challenges with an emphasis on the face, based on my current book project. TikTok, as you already know, is the newest short video sharing app, best known for "\#DanceChallenge." Although it's unclear when and who started the trend, it can be traced back to fall 2019. Since the Covid-19 outbreak in December 2019, the time users spent on TikTok was doubled, and it became the most downloaded app of 2020 with increasing popularity to cope with pandemic-related anxiety.

As Sherril Dodds and Colleen Hooper explain, the face is the central part of human expression and identity. For them, "facial choreography" refers to a preferred facial expression and convention in each dance style, often enhanced by video editing, like the highlighted aggressive facial expression of an African American Krumping dancer on So You Think You Can Dance.

When applying "facial choreography" to TikTok, I argue that there is a rise of "face dance." Face dance differs from facial choreography because face is no longer an adjective, "facial," that elaborates choreography. On TikTok, it is the face that is dancing, and the dancer is the face that is at the center of attention. While "choreography" implies professionalism, dance can refer to a more inclusive activity that everyone can do, from ritual to street festival. It can be a spontaneous, amateur activity, like many social dances.

TikTok dance challenges, as social dance, prioritize socializing and popularity instead of doing the dance right. They mostly consist of simple movements, such as body rolls or swaying hips in a regular tempo-not too fast, not too slow, in an easy going way. A dance challenge is usually recorded by one camera, as a one-shot, focusing on the upper body in portrait orientation, and is front-driven, within a limited space like a bedroom, and time, about 15 seconds.

From proscenium theatre, movie screen, television, computer, and then to tablet and smartphone, the stage actually gets smaller and it is even mobile because the audience now watches video on the go. So today, I argue that we watch dance on the smallest stage in the history of dance, which does not require the previous holistic viewing in theater or what Dodds referred to as focused, completed, intimate viewing.

In a dance challenge, when everyone is doing the same movement without multiple cameras, without enough time or space, the best way to stand out as an individual is to focus on face dance. That includes movements like flirtatious winks, naïve happy smiles, biting lips, rolling eyes, smirking with a shoulder shrug, grimacing, and more. Face dance expresses emotional variety within 15 seconds, such as curiosity, boredom, excitement, awkwardness, just being "cool," or self-pleasure that resonates with a private, intimate moment of orgasmic, sexual ecstasy. Face dance is quick, whimsical, 
drastically changing every second, and unpredictable so that the audience doesn't swipe up. TikTok dance challengers keep the body movement the same, but play with the face with a great deal of improvisation and thus individualization.

It has been rare to see "face dance." Examples can be a proud natural smile after the successful completion of 32 fouettés in Swan Lake; a cathartic grimace during the sharp, passionate footwork in Flamenco; the subtle, uncomfortable, vulnerable face of a postmodern dancer who walks onto the stage naked without any sound; or a father dancing with his daughter at her wedding whose smile says more than happiness. So I argue that TikTok dance is actually imitating the fleeting authenticity of face dance that is hard to capture. But we know that TikTok dancers would stop smiling as soon as they stop recording, so although it looks improvisational and raw, it is still a choreographed authenticity.

During the pandemic, people across the globe suffer from the lack of clean water and hygiene products, unsafe work environments, domestic violence, and racist attacks. In this crisis, we might wonder why there are so many smiley, happy, light-skinned girls dancing in luxurious bedrooms. Future studies can investigate neoliberal capitalism and social media algorithms that support racial, gender, and classed privilege, and how they affect monetization, celebrity culture, and dance labor on social media during and after Covid-19.

Pamela Krayenbuhl: I want to offer one last disciplinary perspective: that of a (dance) media historian who tends to take the long view. Given that, I want to briefly discuss two of my own avenues into making sense of short-form dance on these apps, focused here on TikTok.

My two avenues are medium and/or platform specificity, and restaging old phenomena. First, medium specificity is a film and media studies concept inherited from art historians that asks, essentially: what is unique about $x$ medium? What forms or aspects of human expression does $x$ medium allow or disallow? (and in this case $x$ medium could be painting, photography, film, sculpture, etc.) For our purposes, I am interested not in the larger medium of "the computer" - too big—or even the much smaller category of the "smartphone application" but rather the "short-form video app" specifically-so my question becomes: what is unique about these platforms? And to drill down even further: what unique affordances and constraints are given to or placed upon dance by shortform video platforms like Dubsmash and TikTok? For those of you steeped in technology studies literature, you'll recognize the term affordances from Janet Murray's work on the "digital medium"-she defines them as properties that allow particular uses.

But I'm more interested in TikTok's constraints, so here are two of its major limiting factors: first, that TikTok videos are limited to 15 seconds or up to 60, but it's worth noting that the platform's original 15-second limit tends to be the one that everyone 
cleaves to. And second, the forced vertical or portrait orientation of the app; you can't flip it sideways as you can with many other applications, so dances can't move much laterally. These constraints play perhaps the biggest role in shaping dance style and choreography on the platform. Choreographers construct simple sequences of movement in order to stay under that 15-second marker and in the limited space of a portrait-oriented phone screen, amateur dancers can learn and replicate those simple sequences. As Chuyun discussed, the common thread in TikTok choreographies is a focus on the face, as well as hands, arms, hips, and butt. Footwork is rare and so are fullbody dances, so the age-old complaint of non-dancers having "two left feet?" Not a problem on TikTok.

In the context of Covid-19 and its various lockdowns, we've seen millions of new users flock to the app, so these constrained dances with lots of elbow hits-as if they're hitting the edge of the screen-have been performed by increasingly numerous and diverse people. I want to argue that they collectively constitute a performance of entrapment, mirroring our shared experience of being stuck at home. These dancers are all similarly "stuck" within the frame of their smartphone camera, which is usually propped up or mounted somewhere and notably not moving. Instead of an expansive stage or dance floor, a small rectangle within one's bedroom, bathroom, kitchen, or porch is the only allotted space for embodied expression, and it gets viewed on loop, much like our day is in front of Zoom.

My second avenue here is about restaging old phenomena. Today, as many American critics have pointed out, Dubsmash in the US essentially functions as a space where Black youth create and develop dances within their own community. On the other hand many see TikTok as the space where white youth steal those dances and profit from them. And while this is perhaps an oversimplification (there are numerous popular Black dancers on TikTok as well), I can't help but see a very clear parallel to the last century of American vernacular dances in the United States, especially on media platforms.

In fact, TikTok restages the same processes of "mainstreaming" Black vernacular dances via white bodies that has gone on in every previous generation via a different medium. In the jazz era it was the Charleston and Lindy Hop on film, at midcentury it was rock-nroll dances like the Twist on TV, and now it's hip-hop dances like the Dougie, the Woah, the Wave, the Dab, and so on-and they're online. In every case, a mass medium was the means through which white folks made money performing the dances created by Black folks. With its time and space constraints, TikTok offers a literally condensed version of the same phenomenon.

To conclude, I want to suggest that short-form video apps bear a great deal of continuity with older media when it comes to their circulation of popular dance and the politics thereof. But at the same time, they offer new constraints that help to shape that dance into something very much of the (pandemic) moment. 


\section{Audience Q+A}

Alexandra: I wanted to start with this question of platform specificity, but there's also a significant cross-platform and cross-medium experience; we have a video game, on YouTube, on TikTok, and Dubsmash as a company sharing via Instagram. On one hand TikTok has such primacy right now, and TikTok and Dubsmash are perhaps unique for being "dance first." Dance is what TikTok and Dubsmash are famous for. On the other hand, they need the platforms that predated them and the pandemic moment.

Trevor: A lot of popular TikTok trends are actually longer forms of Vine trends that are being recycled. Something that I noticed with a lot of the teenagers I work with is that they're hyper aware of what works well on the different platforms. My students will say, "let's make a Dubsmash," and then we'll make the same exact song and dance on TikTok, but we change our face- exactly what Chuyun said. Our face dancing is different, the dance goes less hard; it's simplified, it's more playful. And it's amazing to me, these young people are super aware of the systems that everyone's talking about in a very scholarly way, but they're aware of them in a very "hey I just want to get more followers" way.

Pamela: We can see in places like Vine and YouTube and elsewhere the seeds of where these platforms might be going next. My students last quarter were really excited to talk about the influence of TikTok on music video because of the video for the Doja Cat song "Say So." The song became wildly popular in one of these dance trends and the dance, created by a 16-year-old Zoomer, then actually got incorporated into the official music video for the song, which is on YouTube and everywhere now. And I believe the young woman was invited to be in the video with Doja Cat. So I'm thinking about not only what feeds into TikTok, but also what comes out the other end.

Crystal: I wanted to reflect on the cultural specificity. I'm an anthropologist by training, and a lot of what I do involves meeting with people in the flesh to see what they do when they make things for social media. And I was just thinking, if I were to go to any of my young informants in the Asia-Pacific region, and asked them "what is TikTok for?" or "what is Dubsmash for?" I dare say that none of them are going to list dance within the top three things. Speaking to any of my Chinese informants, they use TikTok as a legacy of its predecessor app Douyin, that came out a year ago. For them, TikTok is a way to perform make-up transitions, and shock people that a face that "woke up like this" can look drop dead gorgeous with some transitions, or for fashion. And there is a legacy there of cross-platforming from something domestic and using TikTok to go global. If I were to ask my informants in Malaysia, Indonesia, and Singapore what Dubsmash was for, it would be skits and voiceovers where they mimic actors. They would be very subversive and cheeky with their parodies, trying to make humor a vehicle to talk about political critique. That is a legacy of learning to circumvent state censorship. These are countries where something that is borderline dissident would land you in a police 
station for questioning, but doing so in the vehicle of humor on Dubsmash passes off as frivolity.

So, dance does happen there, but there are two core differences: One, a lot of the young people on TikTok use dance as a way to get noticed by the algorithm, and for other people to see them on the "for you" page. Young people perform great dances, but in the captions and the texts laid over, and in their speech, they outrightly tell you, "I'm doing this so the algorithm puts me on your fyp, and now that I've got your attention here's what I want to say." They're very aware that dance is the popular format that gets them onto people's screens.

The second way I'm seeing dance used as a background is through this concept of refracted publics, where young people believe that if it's just a young woman dancing scantily clad, the algorithm is just going to pass you by, but then in your dialogue, you're talking about genocide, racism, all the state abuse that you believe TikTok's going to remove from the platform, if not for the fact that your fancy trendy dance is helping mask this from the machine algorithmic eye. So I would say that there are a lot of young people not in the dance sphere who are aware of the value of dance and who are using that social capital to embed their messages there as well.

Trevor: I think the regional differences are really important; for example the musicals that are popular on TikTok in the UK are very different than the ones that are popular here in the US. Even though the actual Broadway canon is the same, the ones that the algorithm pushes out in the UK are different.

Chuyun: I was born in South Korea, and I was able to visit my family there last semester because I was teaching online. Because my research is about K-Pop and also social media, I ended up stuck at home watching a lot of TikTok videos. And I noticed the "for you" suggestions were dramatically different from the videos suggested in the United States. I'm not an Algorithm Studies scholar, but to think about the audience reception of dance, we might need to collaborate with people in other fields, in order to get a better idea of how our understanding of a popular trend is actually manipulated by something beyond our human level of expectation.

Colette: So who creates the algorithm?

Alexandra: This is a very important question that's increasingly being handled in Internet Studies, questions about algorithmic bias and who is in fact making those decisions, and who's training the Al "who" is making those decisions. There's speculation that the algorithm on TikTok does focus heavily on facial recognition and also perhaps reads body movement.

Pamela: I'm interested in discourses around these things, and what I'm noticing about the discourse around the algorithm is that it shadow bans fat people, disabled people. Anyone who doesn't fit the normative notion of who's going to look attractive on the 
"for you" page. I follow a number of creators who fit into or identify with one or more of those categories, and they will post really great dances that a lot of people like, but they just won't get the traction. So then they'll post "y'all aren't ready for the conversation about shadow banning," or something like that. Even though we don't have a lot of information about the creation of that algorithm, there's definitely a lot of discourse amongst users critiquing it.

Trevor: If you look at just the top 50 creators on TikTok, the most followed people, they're mostly "attractive" white teenagers or people that fit into "western beauty standards" and so it goes exactly with what we're talking about.

Crystal: I don't think the body is central for many genres of TikTok. But if we consider the body in the equation, there are cultures where people ally with the underdog or the black sheep, and a lot of your cultural capital on the app is linked to the fat body, the disabled body, and people interact with more of such content to disrupt the "Instagram bodies" infiltrating the platform. The intentional design from this app makes it such that we can never have a fruitful conversation about what's the minority, except for when we can prove that these creators have been censored. A recent movement on TikTok by creators is to ask the company ByteDance to be transparent with their moderation policy, because it seems like in some countries just mentioning the word "algorithm" in your captions gets you removed. In some other country markets if you talk about the government, that gets removed. In some other markets showing something that is similar to nipples in coloration-even if you're just wearing a t-shirt-gets you removed. And then you get exploitation, mutilation, and gore: viral. And that standard of moderation is something that we can push the company to be more transparent with. If not, I feel we'll always be in this box of guessing.

What we do know from research is that TikTok operates very differently in specific country markets. For instance, we know that from the way TikTok entered the South Korean market, they cooperated mostly with K-Pop companies, and when you see a lot of people doing dances based on these K-pop songs, it's because the very first batch of them started there. When TikTok broke into the Japanese market, they mass-harvested these humorous high school creators from Vine, and therefore it seems like that is the most popular genre. So, the origin story of every country market shapes what people believe the algorithm is looking for.

There are people you can pay to teach you how to maximize traction on your pagethat swear upon using a combination of songs, that if you like and engage in a specific time slot you are going to be able to be more seen, and we see a lot of mutual following, and collaborations with influencers. And there are also TikTokers who will try something for 100 days and say, "based on a sample size of one, TikTok likes $a, b, c$, and hates 1, 2, 3." All of this is folklore, but if enough people do it, it becomes truth. And that kind of takes the power away from the platform coming to say yes or no. 
Sima Belmar: I'm interested in the ways kids become aware of these processes of dissemination and appropriation.

Trevor: My book is mostly about Black teen girls, and they are hyper aware of this conversation: that someone like Jalaiah Harmon can create a dance, Renegade, and then Charli D'Amelio can get the credit; how white teens are able to appropriate trends and monetize them. They are very much aware. What I noticed though is that the comments in these videos on TikTok and Instagram, for instance, are divided by racial lines where young white people are saying, "this isn't a big deal, it's just TikTok, it's just a dance, we're just having fun." And then people of color, largely Black young people are saying "No, this is not just fun, this is not just a TikTok dance. This is actually our livelihood, and you're taking away our opportunities."

Keisha Turner: I'm curious about how we repair the lack of attribution/erasure of Blackness in these dances. I had my students select a viral dance challenge to learn and present, including what culture the dances came from. The movements were largely hip-hop based but students identified that as "pop culture" rather than Black culture. This is all too prevalent.

Colette: At some point l'm hoping these kinds of things will bring the adults to say "we should probably address racism. We should put it in curriculum." We need to undo this anti-Blackness; this new global community is coming about so quickly, and it is going to require new conversations. One of the things that happened with Jerusalema that was different was because it was a shared experience of the twin toxic traumas of the pandemic and the George Floyd murder. We were sharing this feeling of "I don't get to move," and social distancing, so you had people with wheelchairs, people in Mexican folklorico costumes, people in Ireland who did the challenge. We shared a meaning and then did a dance. So that's not quite appropriation, and that kind of thing can happen on TikTok, which I think is beautiful. But the other part of this globalization that we're experiencing requires finding out ways to undo some of this mess.

Crystal: I think if I can summarize this: social justice is cool on TikTok! If we think back on the predecessor apps, the top creators on Vine were comedic people who had great editing skills; Instagram has been overtaken by fashion influencers. For a Gen Z on TikTok, social justice pursuits, and callout cultures are key platform norms. For this reason, oftentimes posts that go viral are just calling people out. On the one hand this means that a lot of minority creators - certainly in Australia, indigenous creators-often get their voices heard. They make noise, and they challenge when white bodies claim to represent them, because they can speak for themselves in an app that allows them to communicate directly with someone. On the negative side, there are also a lot of TikTokers who commodify social justice by bandwagoning, and if you interrogate them in the comments, many of them don't really know what they're saying. It's become trendy, almost like a badge you wear. 
Pamela: One positive movement l've noticed is an increased trend in giving "dance credit" on TikTok as a result of the Jalaiah Harmon Renegade issue being very public. The New York Times did a big piece, she was on Ellen, so once it became big enough, culture in general was like, "this is bad, we can't have this happening," even though it had been happening for a while, and will continue to happen. So, Dubsmash, Instagram; they had cultures of crediting the original creator of the dance. TikTok did not before Renegade, but now people are giving a " $\mathrm{dc}$ " in their captions. And when they don't, people call them out and say, "where's your dance credit?!" and they'll tag the person who did create it. So as a community, I think they are trying to correct for some of those problems.

Trevor: That's spot on, and I find with TikTok, the big creators set the tone. Once all that happened, Charli D'Amelio, Addison Rae Easterling, they began to give dance credit, which changed the app culture. By the time "Savage" came out two months after the Renegade story blew up, the \#SavageChallenge creator, Keara Wilson, was immediately credited. She immediately had a blue check on Instagram, on TikTok; she had an agent immediately, she had merchandise; Megan Thee Stallion was tweeting about it, and it was a night and day difference from what Jalaiah Harmon had experienced. A lot of creators will now ask in their caption, "hey who created this dance?" if they don't know. One more thing that's changed in the last year is that anything that goes viral, a social media journalist has written an article about it that gives you a very clear lineage.

Chuyun: I think it'll be useful to differentiate finding implications in this fast-changing social media world versus celebrating or glamorizing social media trends. Because what I also notice is that the life span of a viral dance video is really short! TikTok has been here two years, but I cannot even count how many viral dance videos and influencers are out there. In the next few years, maybe the viral video itself won't necessarily mean anything, because anything can go viral. Another thing I notice is the dancers become younger, but they look so mature. The explicit commodification of young girls and their bodies is alarming to me. I think it might be useful for us to see the consequences of fame and how the younger generation is programmed to want to be a star. As a teacher, what can you do when you are guiding students?

Colette: Talking about this kind of sexualized body - the Back to the Root online class series was a response to all of the people who now want to wine their hips; wining of the hips in pre-colonial African cosmology means a lot of things that are not exactly sexual. That gets extracted out as it becomes viral, along with this sexualized, over made-up face and a marketed, commodified body. That is a problem. And that's why we do this, so that people understand what your wining hips might mean, to teach people to look at the body differently, and for women to even imagine themselves differently.

Alexandra: I think that there's a really interesting connection between this appropriation question and the platform affordances. As many of you noted, the 
emphasis is above the knee, and on the face-which allows the persona to be a particular focus, but also eliminates some of the parts of the body that we associate most with movement that we would class as Africanist. The knee bend that Kelly referenced, you can't hardly even see in most TikTok videos! And then videos on other platforms are being influenced by that highly constrained movement. So we have a really specific movement style that's predicated on the technological components, and that continues to reinforce a change in the performance itself.

\section{Biographies}

Alexandra Harlig is an Assistant Clinical Professor at University of Maryland in the University Honors 'Virtually Human' thematic cluster. She holds a PhD in Dance Studies from The Ohio State University. Her research focuses on popular dance forms in media: the political and economic analysis of their production, circulation, and reception, the movement cultures captured, and the platforms utilized. Her multi-disciplinary dissertation Social Texts, Social Audiences, Social Worlds: The Circulation of Popular Dance on YouTube (2019) is available to read and has been downloaded almost 8,000 times. Her writing has been published in The Oxford Handbook of Dance on the Popular Screen and The International Journal of Screendance, for which she is co-editing the special issue This Is Where We Dance Now: Covid-19 and the New and Next in Dance Onscreen with Harmony Bench. Find her on the internet @ReadyMadeAl

\section{Email: aharlig@gmail.com \\ Website: https://alexandraharlig.com/}

A/Prof Crystal Abidin is an anthropologist of vernacular internet cultures, especially internet celebrity, influencer cultures, and social media pop cultures in the Asia Pacific region. She has published over 60 articles/chapters, and her books include Internet Celebrity: Understanding Fame Online (2018, Emerald), Microcelebrity Around the Globe: Approaches to Cultures of Internet Fame (co-edited with Megan Lindsay Brown, 2018, Emerald), Instagram: Visual Social Media Cultures (co-authored with Tama Leaver \& Tim Highfield, 2020, Polity), and Mediated Interfaces: The Body on Social Media (co-edited with Katie Warfield and Carolina Cambre, 2020, Bloomsbury). Her newest book is tumblr (co-authored with Katrin Tiidenberg \& Natalie Ann Hendry, 2021, Polity), with forthcoming books focused on Influencer cultures, Blogshop histories, and TikTok youth movements. Crystal works closely with industry, and her internationally acclaimed research has been recognized by Forbes 30 Under 30 Asia, Pacific Standard Top 30 Thinkers Under 30, and the ABC Top 5 Humanities Fellowship. She is Principal Research Fellow and ARC DECRA Fellow in Internet Studies, and Programme Lead of Social Media Pop Cultures at CCAT, Curtin University. 
Email: crystalabidin@gmail.com

Website: wishcrys.com

Kelly Bowker is a Ph.D. candidate in Critical Dance Studies at the University of California, Riverside where she has received the Chancellor's Distinguished Fellowship, Gluck Fellowship, Digital Humanities Fellowship, and Dissertation Year Program Fellowship. Her research uses critical race studies to examine the way that technology is represented and utilized in both popular and concert dance. Her interdisciplinary research addresses the relationship between identity and how individuals experience and engage with technologies, considering both the active construction of images and the role of representation. She has presented her research at Dance Studies Association as well as the Popular Culture Association.

\section{Email:kbowk001@ucr.edu}

Trevor Boffone is a Lecturer in the Women's, Gender \& Sexuality Studies Program at the University of Houston and a teacher at Bellaire High School. His work using Dubsmash and TikTok with his students has been featured on Good Morning America, ABC News, Inside Edition, and Access Hollywood, among numerous national and local media platforms. He is the author of Renegades: Digital Dance Cultures from Dubsmash to TikTok (Oxford University Press, 2021). He is the co-editor of Encuentro: Latinx Performance for the New American Theater (Northwestern University Press, 2019); Nerds, Goths, Geeks, and Freaks: Outsiders in Chicanx and Latinx Young Adult Literature (University Press of Mississippi, 2020); and Shakespeare and Latinidad (Edinburgh University Press, 2021). His current book project, TikTok Broadway: Musical Theatre Fandom in the Digital Age, explores the relationship between Broadway musicals and the social media app TikTok to demonstrate how the app has democratized fan practices and spaces.

Email: trevor.boffone@gmail.com

Website: https://trevorboffone.com/

Colette Eloi is a sought after guest lecturer and dance facilitator, in African Diaspora Dance. Colette is a third year student at UC Riverside in the Critical Dance Studies Ph.D. program. She earned her B.A. in Development Studies, with an International Relations focus, from UC Berkeley, and an M.F.A. in Interdisciplinary Studies Creative Inquiry, from The California Institute Of Integral Studies, focusing on oral tradition and dance. Her dance home is the dance rich Oakland Bay Area, where she established herself as a culture worker and an award-winning dancer/commissioned choreographer and director of ELWAH Movement. She is a master instructor of Haitian Dance technique and context, which grounds her research interests which are the Pre-colonial Archives of African Rooted dance culture. Her research methodology is dialogical elevating knowledge bases of cultural communities globally and bridging those discourses to the academy. Ms. Eloi is one of the creators of the online dance conference series 
entitled: Back to the Root: The Healing and Spiritual Power of the Spine and the Pelvis in African Diaspora Dance, which will be presenting its 8th in the series which started at the beginning of Covid.

\section{Email: celoi001@ucr.edu}

Pamela Krayenbuhl is an Assistant Professor of Film \& Media Studies in the Culture, Arts, and Communication division at the University of Washington Tacoma. She holds an M.A. and Ph.D. in Screen Cultures from Northwestern University. As a media historian, she researches the long and ever-changing relationship between dance and moving images, with a focus on the aesthetics and politics of dancing bodies in film, television, and new media. Pamela has presented her work at the Dance Studies Association, the International Screen Studies Conference, the Society for Cinema and Media Studies, and the Association for the Study of the Arts of the Present. She is currently working on a monograph about the performance of race and/as masculinity by male dance stars in US midcentury film and television. Beyond academia, as a contemporary ballet dancer and choreographer, Pamela co-founded Modet Dance Collective in Chicago in 2013. She also catalogued the 500+ films of the Ruth Page Collection at the Chicago Film Archives.

Email: pkray@uw.edu

Website: http://pamkrayenbuhl.com

Chuyun Oh (Ph.D. in Performance Studies, UT Austin) is an Assistant Professor of Dance Practice/Theory at San Diego State University. Before pursuing her Ph.D., she was a professional ballet and modern dancer performing across Japan, Korea, Austria, Germany, and the U.S. As a Fulbright scholar, she focuses on performance ethnography and racial and gender identities in transnational popular dance on social media. Her work has appeared in Dance Research Journal; Dance Chronicle; The Journal of Popular Culture; Journal of Intercultural Communication Research; Communication, Culture \& Critique; The International Journal of the History of Sport; The Journal of Fandom Studies, and Text and Performance Quarterly. Since 2016, her works have received three Top Contributed Performance awards and a Top Paper award from the Performance Studies Division at the National Communication Association. She is serving on the Editorial Board of Text and Performance Quarterly and Review of Communication.

Email:coh@sdsu.edu 
Resources in Order of Mention

Abidin, Crystal. TikTok and Youth Cultures. Emerald Publishing. Forthcoming, 2022.

TikTok Cultures Working Group bibliography. https://tiktokcultures.com/bibliography

Kaye, D. Bondy Valdovinos, Xu Chen, and Jing Zeng. "The Co-evolution of Two Chinese Mobile Short Video Apps: Parallel Platformization of Douyin and TikTok." Mobile Media \& Communication. 30 Aug. 2020. https://doi.org/10.1177/2050157920952120

Boffone, Trevor. Renegades: Digital Dance Cultures from Dubsmash to TikTok. New York: Oxford University Press, forthcoming 2021. https://global.oup.com/academic/product/ renegades-9780197577684? promocode=AAFLYG6\&lang $=$ en\&cc $=$ us

\#BlackLivesMatter Challenge Video: https://www.instagram.com/p/CBE9MNvnZzV/ ?igshid=3161 ekwi6y9

Hissong, Samantha. "How South Africa's 'Jerusalema' Became a Global Hit Without Ever Having to Be Translated" Rolling Stone. 16 Oct. 2020. https://www.rollingstone.com/pro/news/jerusalema-global-dance-hit-south-africaspotify-1076474/

The Original TikTok \#Jerusalema Dance Challenge from Angola group Fenomenos do Semba https://youtu.be/MI-IniZddzM

\#Jerusalema Dance Challenge compilation https://www.instagram.com/p/ CGfABsVJT8E/?igshid=1sg2ai1hvu817

Oh, Chuyun. K-pop Dance: Fandoming Yourself on Social Media. Forthcoming, 2021.

Dodds, Sherril and Colleen Hooper. "Faces, Close-ups and Choreography: A Deleuzian Critique of So You Think You Can Dance." The International Journal of Screendance 4 (2014). https://doi.org/10.18061/ijsd.v4i0.4524

Dodds, Sherril. "On Watching Screendance." The International Journal of Screendance 10 (2019). https://doi.org/10.18061/ijsd.v10i0.6726

Murray, Janet H. Inventing the Medium: Principles of Interaction Design as a Cultural Practice. Cambridge, MA: MIT Press, 2011.

Doja Cat. "Doja Cat - Say So (Official Video)." Uploaded 27 Feb 2020. https://www.youtube.com/watch?v=pok8H_KF1FA

Abidin, Crystal. "From 'Networked Publics' to 'Refracted Publics': A Companion Framework for Researching 'Below the Radar' Studies." Social Media + Society 7.1 (2021): 1-13. https://doi.org/10.1177/2056305120984458 
Abidin, Crystal. "Mapping Internet Celebrity on TikTok: Exploring Attention Economies and Visibility Labour." Cultural Science Journal 12.1 (2021): 77-103. https://doi.org/10.5334/csci.140 